\title{
Follicular Dendritic Cell Sarcoma Arising in Hyaline-Vascular Castleman Disease of Mediastinum: A Case Report
}

\author{
Song-Yi Choi ${ }^{\mathrm{a}}$, Jin-Man Kim, c
}

\begin{abstract}
Follicular dendritic cell (FDC) sarcoma is a rare neoplasm that is grouped as histiocytic and dendritic cell neoplasm. It can occur primarily in lymph nodes but also in extranodal sites. Follicular dendritic cells are nonlymphoid, nonphagocytic accessory cell in the immune system. Their dendritic cell nature can be demonstrated by the various FDC markers, such as CD21, CD23, CD35, R4/23, and $\mathrm{Ki}-4 \mathrm{p}$. FDC sarcoma may occur in association with Castleman disease in $10-20 \%$ cases. We experienced a case of FDC sarcoma associated with hyaline vascular type-Castleman disease (HVCD). A 62-year-old woman presented a posterior mediastinal mass shown by computed tomography. The resected mass was an encapsulated solid mass, measuring $5.5 \times 4 \mathrm{~cm}$ in size. Microscopically, the tumor was composed of spindle cells showing a fascicular and storiform arrangement. There are some areas reminiscent of HVCD. The tumor cells were positive for the FDC marker CD21.
\end{abstract}

Keywords: Follicular dendritic cell sarcoma; Mediastinum; Castleman disease; CD21

\section{Introduction}

Follicular dendritic cell (FDC) sarcoma, also known as dendritic reticulum cell tumors, is a rare neoplasm [1-5]. The

Manuscript accepted for publication May 3, 2011

${ }^{a}$ Department of Pathology, Chungbuk National University Hospital, Cheongju, South Korea

${ }^{\mathrm{b}}$ Departement of Pathology, Cancer Research Institute, Regional Cancer Center and Infection Signaling Network Research Center, Chungnam National University School of Medicine, 6 Munwha-Dong, Jung-Gu, Daejeon 301-131, South Korea

${ }^{\mathrm{c} C}$ orresponding author: Jin-Man Kim, Email: jinmank@cnu.ac.kr

doi: $10.4021 / \mathrm{jmc} 215 \mathrm{w}$ predilection sites are lymph nodes of the neck, axilla and mediastinum $[1,4]$. A variety of extranodal sites may be affected, particularly the tonsils, spleen, gastrointestinal tract, and intra-abdomen $[1,3,4]$. The patients are usually adults with a wide age range [3, 4]. There is no sex predilection. FDCs, accessory cells of the lymphoid system, present antigens and immune complexes to B lymphocytes and regulate proliferation and immunoglobulin secretion of germinal B cells $[1,6,7]$. FDC sarcoma is a neoplastic proliferation of spindle to oval cells showing FDC differentiation by cytomorphologic and ultrastructural features and immunoreactivity for FDC markers, such as CD21, CD23, CD35, R4/23, and $\mathrm{Ki}-4 \mathrm{p}[1,6,8,9]$. FDC tumors were first described by Monda et al. in 1986 [10]. Most of the data on FDC sarcoma is based on single cases or small series, and the natural history of this disease has not been well established [4, 5, 8]. FDC sarcoma may occur in association with Castleman disease, usually the hyaline vascular type, in about $10-20 \%$ of cases $[4,11]$. Castleman disease precedes the follicular dendritic cell sarcoma or the two lesions may occur simultaneously [4]. Reported herein is a patient with a FDC sarcoma associated with hyaline vascular type-Castleman disease (HVCD) of the mediastinum, a case rarely documented.

\section{Case Report}

A 62-year-old woman presented with dyspnea for 3 years. Computed tomography revealed a posterior mediastinal mass, measuring $10.7 \times 7.6 \mathrm{~cm}$ in size. She refused further evaluation and treatment. Two years later, she revisited our hospital for the same symptoms. The size of the mass increased to $11.3 \times 10.4 \mathrm{~cm}$ on computed tomography (Fig. 1A). There were also multiple enlarged lymph nodes in paratracheal area. The patient underwent a percutaneous needle biopsy. We suggested a possibility of HVCD.

Immunohistochemical studies were performed on formalin-fixed, paraffin-embedded tissue. Primary antibodies against CD20, CD21, CD23, CD3, CD10, CD68, CD34, TdT, cytokeratin, alpha-smooth muscle actin, desmin, vimentin, S-100 protein, epithelial membrane antigen (EMA), anaplastic lymphoma kinase-1 anigen (ALK-1), and Ki-67 


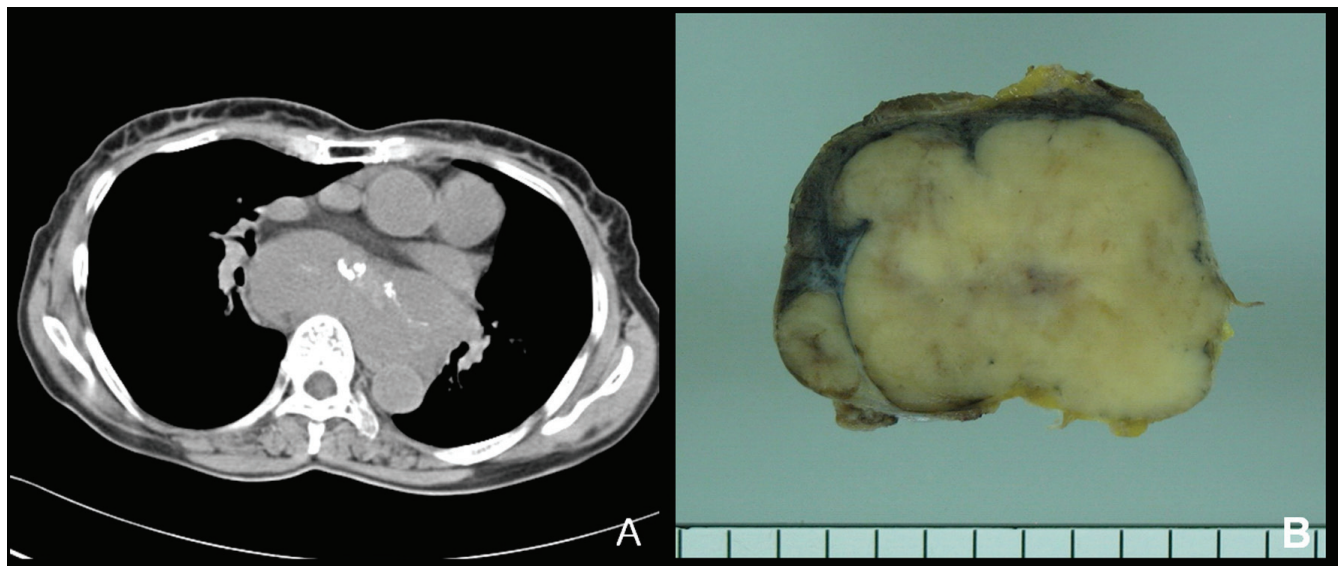

Figure 1. (A) In computed tomography, a huge lobulated solid mass is seen in the posterior mediastinum. (B) Grossly, the resected tumor is solid, vaguely nodular and tan to grayish cut surface. Adjacent enlarged lymph nodes are included.

antigen were used.

The removed specimen was an encapsulated solid mass, measuring $5.5 \times 4 \mathrm{~cm}$ in size. It was multinodular and showed conglomerated appearance. The cut surface was homogeneous, vaguely lobulated, and tan to grayish in color
(Fig. 1B). The resected specimen was composed of several conglomerated lymph nodes. The nodal architecture was mostly effaced by a neoplastic proliferation composed of spindle cells. The periphery of the tumor and a separated small lymph node showed several atretic follicles, separated

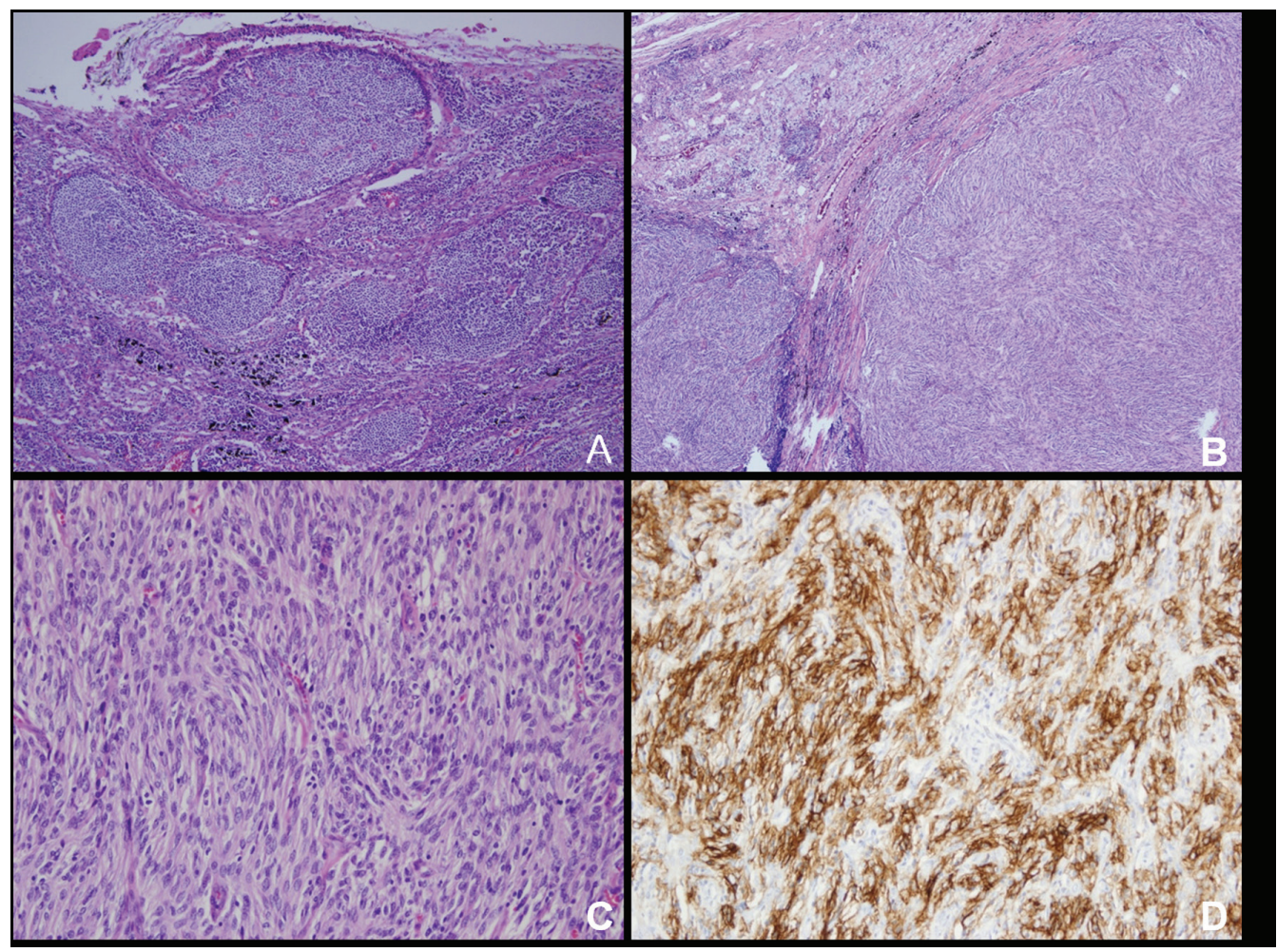

Figure 2. (A) The non-neoplastic lymphoid follicles show depletion of germinal center lymphocytes with increased FDCs and are penetrated by small capillaries. (B) Conglomerated lymph nodes are mostly replaced with neoplastic spindle cells arranged in fascicles. (C) The tumor cells show storiform arrangement that have indistinct cell borders and eosinophilic cytoplasm. Small lymphocytes were splinkled throughout the tumor. (D) Immunohistochemically, the tumor cells demonstrate strong cytoplasmic expression for CD21. Original magnification: A, 40 X; B, 100 X; C, 200 X; D, 200 X. 
by highly vascularized interfollicular areas. These lymphoid follicles showed depletion of germinal centers including centroblasts and centrocytes, and were penetrated by small capillaries, frequently with hyalinized walls, the features reminiscent of HVCD (Fig. 2A). The tumor consisted irregular-shaped lobules, separated by dense fibrous stroma (Fig. 2B). The tumor cells showed a fascicular and storiform arrangement and had indistinct cell borders and eosinophilic cytoplasm. The nuclei were oval to elongated, with vesicular or finely dispersed chromatin and prominent nucleoli (Fig. $2 \mathrm{C})$. There was a sprinkling of small lymphocytes throughout the tumor.

The tumor cells were positive for the FDC marker CD21. These markers highlighted the delicate interconnecting cell processes of the tumor cells (Fig. 2D). The tumor cells were negative for all the other markers listed above. The associated lymphocytes were more commonly TdT-positive T cells (CD3) than B cells (CD20). The Ki-67 index of the tumor cells was $20 \%$.

\section{Discussion}

Follicular dendritic cell sarcoma is a rare neoplasm, with most studies representing single case reports or small series $[4,5,8]$. There is little known etiology of FDC sarcoma [1, 4]. FDC sarcoma affects the lymph node in more than onehalf of the patients. The common sites are cervical lymph nodes, followed by axillary, mediastinal, mesenteric and retroperitoneal lymph nodes [4]. Patients usually present with a slow growing and painless mass. But systemic symptoms may be shown in patients associated with EBV [7]. The biologic behavior of FDC tumors is more akin to that of a low-grade sarcoma than a malignant lymphoma $[1,8,12]$. This tumor exhibits a substantial malignant potential and a local recurrence. The metastatic rate is more than $40 \%$ and the local recurrence rate is more than $25 \%$. Common sites of metastasis are lymph nodes, lung, and liver [1, 3, 4]. High grade histologic features such as high mitotic count (more than 5/10 HPF), significant cellular atypia and coagulative necrosis may be associated with poor prognosis [5]. The current case demonstrated predominantly low-grade histologic features.

Fonseca et al., in a review of the literature on 12 cases of FDC sarcoma, reported relapse rates of $40 \%$ with surgery, $56 \%$ with chemotherapy alone, and $25 \%$ with surgery and radiation combined. But there are no prospective studies of treatments and outcomes in patient with FDC sarcoma [5, 13].

FDC sarcoma may occur in association with Castleman disease in about $10-20 \%$ of cases, either concomitantly or after several years $[1,3,4,8]$. It can occur both in a nodal and extranodal site, usually in the hyaline vascular type. There is a proliferation of FDCs in the interfollicular spaces.
In addition FDC dysplasia with chromosomal abnormality is identified in some follicles of HVCD. These dysplastic FDCs may form tumor-like lesions and have clonality and aberrant expression of cell adhesion molecules and growth factor receptor [8]. Therefore a hyperplasia-dysplasia-neoplasia sequence was suggested as an explanation for the evolution of FDC sarcoma in the background of Castleman disease $[4,8,11]$.

Many authors have suggested various etiologic factors of this evolution sequence. Sun et al. found EGFR over-expression in both FDC sarcoma and Castleman disease, but not in FDCs in reactive germinal centers [14]. EGFR signaling pathway promotes FDC persistence, which may result in evolution of sarcoma with accumulation of mutation. Because FDCs express CD21, EBV has been postulated as an etiologic factor [9]. Nevertheless EBV is usually negative except for FDC sarcoma occurring in the liver and spleen with an inflammatory pseudotumor-like histologic appearance. Thus EBV does not seem to play a role in the transformation process. Chan et al. documented literature reviews of 13 FDC sarcoma cases associated with Castleman's disease [2]. Thoroughly reviewing the English literature, there were no other literatures except these 13 cases. Except for 1 case which was associated with plasma cell type, most cases were associated with hyaline vascular type. The most common site was intra-abdominal $(\mathrm{n}=5)$, followed by peripheral lymph node $(\mathrm{n}=4)$, mediastinum $(\mathrm{n}=2)$, soft tissue $(\mathrm{n}=2)$ and nasopharynx $(\mathrm{n}=1)$. The current case occurred in the posterior mediastinum, in contrast to the previous cases occurring in the anterior mediastinum.

In summary, this reported case of FDC sarcoma is a rare lesion. With regard to the posterior mediastinum, FDC sarcinoma arising in HVCD has not been documented in this location.

\section{Grant}

This research was supported by the National Research Foundation of Korea (NRF) grant funded by the Korea government (MEST) (No. 2010-0001284 : 2010-0001287) and by a grant from the National R\&D Program for Cancer Control Ministry of Health \& Welfare, Republic of Korea (No: 0720560).

\section{Conflicts of Interest}

We do not have any conflicts of interests.

\section{References}

1. Choi PC, To KF, Lai FM, Lee TW, Yim AP, Chan JK. 
Follicular dendritic cell sarcoma of the neck: report of two cases complicated by pulmonary metastases. Cancer 2000;89(3):664-672.

2. Chan AC, Chan KW, Chan JK, Au WY, Ho WK, Ng WM. Development of follicular dendritic cell sarcoma in hyaline-vascular Castleman's disease of the nasopharynx: tracing its evolution by sequential biopsies. Histopathology 2001;38(6):510-518.

3. Christopher DMF. Diagnostic Histopathology of Tumors. 3rd ed. Philadelphia: Elsevier, 2007:1240-1242.

4. Jaffe ES, Harris NL, Stein H, Vardiman JW. WHO classification pathology and genetics of tumors of hematopoietic and lymphoid tissue. Lyon: IARC Press, 2001:286-288.

5. Soriano AO, Thompson MA, Admirand JH, Fayad LE, Rodriguez AM, Romaguera JE, Hagemeister FB, et al. Follicular dendritic cell sarcoma: a report of 14 cases and a review of the literature. Am J Hematol 2007;82(8):725-728

6. Sander B, Middel P, Gunawan B, Schulten HJ, Baum F, Golas MM, Schulze F, et al. Follicular dendritic cell sarcoma of the spleen. Hum Pathol 2007;38(4):668-672.

7. Granados R, Aramburu JA, Rodriguez JM, Nieto MA. Cytopathology of a primary follicular dendritic cell sarcoma of the liver of the inflammatory pseudotumor-like type. Diagn Cytopathol 2008;36(1):42-46.

8. Agaimy A, Wunsch PH. Follicular dendritic cell tumor of the gastrointestinal tract: Report of a rare neoplasm and literature review. Pathol Res Pract 2006;202(7):541548.

9. Choi JW, Lee JH, Kim A, Kim CH, Chae YS, Kim I. Follicular dendritic cell sarcoma arising in the dura mater of the spine. Arch Pathol Lab Med 2006;130(11):17181721.

10. Monda L, Warnke R, Rosai J. A primary lymph node malignancy with features suggestive of dendritic reticulum cell differentiation. A report of 4 cases. Am J Pathol 1986;122(3):562-572.

11. Kazakov DV, Morrisson C, Plaza JA, Michal M, Suster S. Sarcoma arising in hyaline-vascular castleman disease of skin and subcutis. Am J Dermatopathol 2005;27(4):327-332.

12. Perez-Ordonez B, Erlandson RA, Rosai J. Follicular dendritic cell tumor: report of 13 additional cases of a distinctive entity. Am J Surg Pathol 1996;20(8):944955.

13. Fonseca R, Yamakawa M, Nakamura S, van Heerde P, Miettinen M, Shek TW, Myhre Jensen O, et al. Follicular dendritic cell sarcoma and interdigitating reticulum cell sarcoma: a review. Am J Hematol 1998;59(2):161167.

14. Sun X, Chang KC, Abruzzo LV, Lai R, Younes A, Jones D. Epidermal growth factor receptor expression in follicular dendritic cells: a shared feature of follicular dendritic cell sarcoma and Castleman's disease. Hum Pathol 2003;34(9):835-840. 